\title{
23 \\ IN A MOOD TO MAKE SENSE OF TECHNOLOGY: A LONGITUDINAL STUDY OF DISCURSIVE PRACTICES AT THE LONDON AMBULANCE SERVICE
}

\author{
Kathy McGrath \\ Department of Information Systems \\ London School of Economics and Political Science \\ London \\ United Kingdom
}

\begin{abstract}
This paper addresses how an organization that experienced a major disaster when implementing an information system has attempted to rebuild its sense of identity, while responding to sectoral and national mandates that it continue to deploy information technology as a means of improving its performance. The organization is the London Ambulance Service (LAS). The disaster occurred 10 years ago during the LASCAD (LASCOmputer Aided Despatch) implementation of October 1992. The institutions that mandate the continued adoption of information technology are the Department of Health, the UK government, and the popular press, acting as guardians of the public interest. This research addresses the discourses about information systems (IS) implementation that have taken place at the LAS over the last 10 years, how they have been framed by institutions, as well as informed by local memories. Moreover, it addresses the emotional medium in which these discourses have taken place, following the events of October 1992. In this way, the research considers the emotional and cognitive dimensions of IS implementation and use, or how an enduring mood and a pervasive mode of arguing and acting interpenetrated in three IS projects at the LAS during the last decade.
\end{abstract}

The original version of this chapter was revised: The copyright line was incorrect. This has been corrected. The Erratum to this chapter is available at DOI: 10.1007/978-0-387-35634-1_28 


\section{INTRODUCTION}

During the 1990s, information systems (IS) failure became a popular area of research. A number of high profile disasters were featured in a stream of publications, for example projects at American Airlines (Oz 1994), the New Zealand Education Department (Myers 1994), the London Ambulance Service (Beynon-Davies 1995; Introna 1997), the French Railways (Mitev 1996), and the London Stock Exchange (Drummond 1996). Following in the wake of this interest, an area of research that might now be addressed is how experience of such a disaster affects organizational members as they approach similar tasks in the future, and how they act within this attunement with the situation. These are the issues that are addressed by this research. It examines the discursive practices of staff at the London Ambulance Service (LAS) as they undertook further IS implementations following a disastrous effort in 1992, arguing that these practices were cognitive-emotional ways of arguing and acting.

Drawing on a longitudinal field study, I suggest that improvisation was a pervasive mode of arguing and acting within the organization, which was supported to varying degrees in IS implementations, while the emotional medium in which these implementations took place was one of anxiety, which at times intensified to fear. In this way, I explore how a mood and a mode of arguing and acting interpenetrated in three IS projects at the LAS during the last decade. Following this introductory section, I develop the theoretical basis for the study, followed by a description of the research approach adopted in this setting. Then I present a narrative tale of a particular day at the case organization, a day on which a new information system was implemented. I draw on the narrative to examine how social institutions and local memories have influenced the course of IS implementations at the LAS. Finally, I present conclusions from the study.

\section{THEORETICAL BASIS}

This research takes its concept of discourse from the later works of Michel Foucault. In this way, discourse is not just concerned with what we speak, but also with whom speaks it, and how it is enacted. Discourse has three elements: a community in which the discourse emerges, institutions with knowledge and authority which delimit the discourse, and grids of intelligibility which enable particular practices to be related to each other in a specific type of discourse. These ideas are encapsulated in Foucault's (1980) concept of a regime of truth, which focuses on discursive and nondiscursive practices in which knowledge and power, or ways of arguing and acting, are central concerns.

So, I employ a regime of truth framework as a broad theoretical construct within which I examine improvisation as a specific way of arguing and acting 
identified within the LAS community. Moreover, I adopt the view that Foucauldian concepts have yet to be widely exploited for emotionality (Fineman 2000), and so I examine anxiety as an emotional medium within which arguing and acting about IS implementation took place. In this way, I employ several theoretical concepts to examine detailed working practices at the LAS, while setting that examination within a Foucauldian tradition in which institutions-as authoritative, standardized, social patterns of activity in their environment - are seen to constitute actors and action in organizations (Hasselbladh and Kallinikos 2000).

\subsection{Theoretical Perspectives on Improvisation}

Weick (1998, p. 546, citing Ryle 1979) argues that all behavior is in some way improvised, since it "mixes together a partly fresh contingency with general lessons previously learned." In this way, retrospect or memory is important during improvisation. Furthermore, there are degrees of improvised activity from minor interpretations and embellishments to major variations and transformations (ibid), in which the form of the object to be embellished (whether it is a jazz melody or a dialogue with a caller to the ambulance service) comes into play.

On the issue of providing automated support for improvisation, Ciborra (1999) argues that "most systems (and software) design approaches...aim at cleansing [improvisation] through structured procedures and formalization of information" (p. 146). In this way, IT applications frequently automate incompetent behavior by being based on ideas of formal decision making and ignoring the gaps between what is planned and what emerges during IS implementation and use. Moreover, during systems development activities such as data modeling, designers aim to reach closure on the data values the application will handle, restricting the scope for interpretation and the opportunities for learning during system use. In this way, designers' attempts to capture highly relevant, localized data engage the backlash of experience in which the data are cleansed of their richness so that they seem to have very little meaning at all to those that would use them.

\subsection{Theoretical Perspectives on Mood}

Although emotionality has received limited attention in IS research, it has developed into a subdiscipline in other fields (Fineman 2000). Writers argue that affective phenomena include emotions, moods, and dispositions (Oatley and Jenkins 1996), and they define these phenomena in terms of their duration or 
stability, intensity, and target (Harlos and Pinder 2000). Without wanting to be too prescriptive about such distinctions, in this paper I explore mood as an affective phenomenon that can be short-lived or very enduring (ibid), a way of being in the world that can change, although we are never without a mood (Ciborra 2001).

Mood is both an emotional medium in which we act (ibid), and an outcome of activity (Fineman 2000). Although we may not always be aware of our moods or what gives rise to them, they may become intense at times, for example when anxiety intensifies to fear (which some writers argue is a step-change from a mood to an emotion) as an anticipated danger seems more imminent. Indeed, fear is very intense and has an especially long half-life (Harlos and Pinder 2000), which suggests why anxiety can endure long after the imminent danger has passed, and why those who have experienced fear can vividly recall the experience years later. Ciborra (2002), drawing on Heidegger (1995), suggests that we may study moods by examining the way we move within them-in the way we seek to drive them away.

\subsection{Moving Within a Mood of Anxiety or Fear}

In his account of the Mann Gulch disaster, Weick (1993) argues that Dodge, the smoke jumpers' leader, attended to his mood of fear by engaging in an act of improvisation and bricolage, in which he made creative use of the resources at hand to escape one fire by starting another. The only other survivors of the fire, Rumsey and Sallee, attended to their fears by sticking together while the rest of the team scattered. In this way, they improvised a different role system, but one that preserved their identity as members of a team. In this view, then, improvisation is a way of attending to anxiety or fear - a way that can seem quick, simultaneous, and brilliant, as in Dodge's case, but in general is far more tentative, open-ended and banal, as in the case of treating a medical condition (Weick 1998). So, Weick argues, improvisation is a mindset-a way of arguing and acting within a mood, but a cognitive phenomenon that can attend to an emotional one.

In a more radical interpretation of the Mann Gulch disaster, Ciborra (2001) argues that Dodge drove away his mood of fear in an act of improvisation, so that improvisation became his attunement with the situation. In this way, he suggests that improvisation is a mood and not a mindset, an emotional medium in which we act and not a purely cognitive process. The position adopted in this research is that thinking is always brushed with emotion (Fineman 2000) and that feeling does not occur in a vacuum devoid of a cognitive dimension. So, our ways of arguing and acting are cognitive-emotional ways, in which a thinking/ feeling guide our actions. 
Weick (1993) discusses structuring for resilience in the face of danger or threat. At Mann Gulch, he argues, the process of structuring (the way meanings and frameworks constitute one another) was very unstable so that people were unable to negotiate strangeness with the result that their anxiety turned to panic. A loss of organization reduced their capacity to act, so that structures and actions (or frameworks and meanings) destroyed rather than constituted one another. Arguing that the most resilient way of structuring may be one that is simultaneously constitutive and destructive, Weick offers two scenarios, which deal with a loss of organization and a decline in meaning. First, when an existing structure is threatened, individuals try to work out what the new world means for them, which may lead them to rebuild their social ties in line with new meanings. Alternatively, when people are puzzled about what they are trying to do so that meanings are unclear, they focus on clarifying social relations, and as these become clearer the world is less puzzling to them and their capacity to act tends to increase. In each case, an existing way of structuring is being destroyed but a new one is being built. Weick suggests that the first scenario was visible in the improvised actions of the survivors at Mann Gulch. At the LAS, both the resilient and the unstable forms were evident in the three projects I will examine later.

\section{RESEARCH APPROACH}

I explore the above arguments in the context of IS implementation and use at the LAS by drawing on a narrative that describes an exceptional day in the history of the service, one on which organizational members recalled a past experience in an intense emotional medium. In choosing to describe an exceptional day, I follow Foucault, by exploring life on the margin, and Van Maanen (1988), by recounting an impressionist tale. I argue that such examples merely heighten what occurs in our usual, everyday practices and, in recalling an event that had some drama attached to it, I invite readers to relive it to get a sense of the actors' moods. I include some description of the cultural practices of this community, with pointers to how such practices are influenced by social institutions, to give a sense of how the discourse was institutionally framed as well as locally informed. In this way, I call the narrative a quasi-impressionist tale, since it also exhibits some of the traits of critical and realist tales (Van Maanen 1988).

\subsection{Research Setting}

The LAS may be understood as an organization providing pre-hospital patient care, where patients are any of about 8 million people who, while living, 
working, or visiting within an area of 620 square miles around London, either request an ambulance or have one requested on their behalf. Emergency calls for an ambulance cannot be refused, even if patients do not appear to have serious or life-threatening conditions. So during the last 10 to 15 years, environmental changes such as increased levels of care within the community, and societal attitudes such as heightened public expectations influenced by initiatives like the Patient's Charter (Department of Health 1996), have put additional pressures on ambulance services.

Fueled by these changes, call volumes have risen by over 50 percent in 10 years. The LAS alone receives over 1 million emergency calls annually-about 1 in 4 of all calls made to the ambulance services in England and Wales. Over 80 percent of the LAS's 3,400 staff work in accident and emergency (A\&E) operations, the group whose IS implementation efforts are the focus of this study. Members of the A\&E group include over 2,000 vehicle crew staff responding to emergency calls from 70 ambulance stations around London, about 350 control room staff taking calls at headquarters and allocating them to crews, and smaller operational support units concerned with staff training and standards development.

\subsubsection{Ambulance Performance Standards}

Key measures of performance for UK ambulance services are defined in nationally recognized standards for ambulance response times. Prior to a government-initiated review (Chapman 1996), these performance standards, then called ORCON (Operational Research Consultancy) standards, required that

- 50 percent of emergency calls should receive a response within 8 minutes (i.e., the crew should be at the scene within that time), and

- 95 percent of emergency calls should receive a response within 14 minutes (in urban areas) or 19 minutes (in rural areas).

ORCON standards emphasized speed of response in a regime that treated all calls with equal priority. The 1996 review identified as a key requirement substantially reducing premature deaths from coronary heart disease, and hence modifying ORCON standards. Without de-emphasizing speed of response, the new standards require that emergency calls are prioritized according to the clinical needs of patients and that vehicles are despatched based on the priority assigned to each call. So, since 31 March 2001, ambulance services have been charged with responding to 
- 75 percent of category A (the highest priority) calls with an appropriate (ambulance or fast response car or bike) resource within 8 minutes, and

- 95 percent of category $\mathrm{B}$ and category $\mathrm{C}$ (the lower priorities) calls with an ambulance resource within 14 minutes (in urban areas) or 19 minutes (in rural areas).

In category A cases where a fast response vehicle (one that is strategically positioned so that it can respond quickly) is despatched, it must be backed up by an ambulance within 14/19 minutes of call receipt in 95 percent of cases. By 2003, ambulance services will be required to respond to 90 percent of category A calls within 8 minutes (Chapman 1996; Department of Health 1999). Although these standards have been relaxed for the LAS in view of the acute nature of social problems, assaults on staff, and traffic congestion in London, the service must achieve full compliance with the March 2001 targets by December 2002. In the new environment, institutions such as the Department of Health, and ultimately the UK government, seek to replace the ORCON discourse, that all calls have equal priority, with a discourse of "despatching by priority" or "responding to patients based on clinical need." In this way, institutions frame the discourse that is enacted at the LAS, and employ the ambulance performance standards as grids of intelligibility to compare the performance of one service with another.

\subsubsection{The LASCAD (London Ambulance Service Computer Aided Despatch) Project}

In 1992, the LAS implemented the LASCAD system in an effort to improve its performance against ORCON standards. At the time it was the UK's worst performing ambulance service (House of Commons Select Committee 1995). The LASCAD implementation attempted to automate the entire process of call taking, allocating and despatching vehicle crews to calls, tracking vehicle locations, and providing management information for performance assessment and resource management and planning purposes. Voice communications between control room staff and vehicle crews would occur in exceptional circumstances only, replaced by electronic data transfer, and vehicle location monitoring would be achieved via aerials fitted to the vehicles, rather than having crews radio in their positions. The LASCAD system was implemented in the early hours of 26 October 1992. By mid-morning, there were serious problems; within 36 hours the LAS had reverted to semi-manual operations; and on 4 November 1992, the system collapsed and full manual operations were resumed (Page et al. 1993). 
Accounts of this project are legion (for example, Beynon-Davies 1995; Financial Times 1993; Hougham, 1996; Introna 1997; Page et al. 1993; Wastell and Newman 1996). Reinterpreting the public inquiry report (Page et al. 1993), they argue that the LASCAD project attempted to introduce a disciplinary technology (Introna 1997) in a hostile industrial relations climate (Wastell and Newman 1996), in which a managerial and technical failure occurred (BeynonDavies 1995; Hougham 1996). Since 1992, institutional scrutiny of the LAS has been intense. In this examination, some staff feel poorly served by external commentators, especially members of the press, who they believe sensationalize events when providing a considered assessment of them would be more helpful.

\subsubsection{The CTAK (Call Taking) Project}

Manual operations continued at the LAS until 1996, when the CTAK system was implemented. This system provides automated support for call taking activity only, and in this way CTAK was substantially less ambitious than LASCAD. The CTAK system replaced a manual method of recording call details on slips of paper (and using human runners to transport the slips from call takers to ambulance allocators) with online data entry and supporting enquiry and printing facilities. An online gazetteer was included, which determines a grid reference for the allocator based on the location of the incident. Allocators were given access to view and print call details, but they continued to use a box method to maintain details about where resources were located and which calls they were attending. Moreover, radio and telephone endured as the methods for despatching ambulances to calls. The design philosophy for the CTAK system is expressed in the user view that it was "something that... helped us do what we did in the same way that we had always done it." Following implementation of the system, the improvement in the LAS's performance against ORCON standards was deemed sufficient for the service to be granted self-governing status as a National Health Service (NHS) trust in April 1996.

\subsubsection{The PDS (Priority Despatch System) Project}

The review of ambulance performance standards (July 1996) identified a requirement to prioritize emergency calls and despatch resources to patients based on the priorities assigned. Thus, during 2000, the LAS modified the CTAK system to incorporate call prioritization, so that its manual systems for allocating and despatching resources could function on a priority basis. To achieve this task, a packaged application, which I will call PDS, was acquired and embedded within the CTAK system. Through a structured series of question 
and answer protocols and inscribed rules, PDS suggests a clinical determinant indicating the severity of a patient's condition, enabling clinical priorities to be assigned to emergency calls. In line with the supplier's recommendation, the LAS installed a card-based version of the system at first to ease transition to the automated version. Implementation of call prioritization was accompanied by the introduction of a quality assurance unit, which monitors compliance with the new discipline. So PDS, like CTAK, had call taking activity as its primary focus, although despatch decisions are now dependent on the outcomes of an automated call prioritization process. In March 2001, the LAS met one of its response time targets for the first time, but its performance figures still lag those of other UK ambulance services.

\subsection{Research Method}

The empirical work reported here took place between February 2000 and February 2001, in a longitudinal study that followed the progress of the PDS implementation. During this period, I conducted 38 interviews of 60 to 150 minutes duration. These meetings involved staff from different hierarchical levels and functional groups, including board directors, departmental managers, members of the staff training unit, IT specialists, and quality assurance advisors. I attended 21 project meetings and 6 staff training sessions relating to the PDS implementation, and spent another 75 hours observing front line operations, both in the LAS control room and at emergency scenes. I drew upon several documentation sources relating to current and past IS projects, including service and technology strategies, project plans and meeting minutes. Finally, I referred to public inquiry reports into the performance of the LAS (Page et al. 1993; House of Commons Select Committee 1995).

My aim was to build a contextually sensitive (Pettigrew 1990) account, which considered the institutional framing, the grids of intelligibility and their local enactment at the LAS over the last 10 years. These sensitizing concepts provided "a general sense of reference and guidance in approaching empirical instances" (Blumer 1954, p. 7), and themes relating to them were identified and developed in a qualitative approach to data analysis. In this way, the Foucauldian concept of a regime of truth informed the data collection, but I did not approach the task with preconceived notions about what the specific ways of arguing and acting at the LAS might be. Rather I focused on what institutions such as the Department of Health declared about patient care and good performance, and set out to discover how this was enacted at the LAS, mindful of the events of October 1992.

As I wrote up and analyzed my field notes, different actors' interpretations of responding to and caring for patients, performing well, and the role of 
information technology in supporting their work, prompted me to see degrees of improvisation and anxiety in their ways of arguing and acting. These themes then informed further data collection efforts, and in this way the study remained open to influences from the field data, which suggested that initial theories be enhanced (Walsham 1995). My role started as one of participant-observer, but as time went on I was asked to comment on situations by staff at all levels. In this way, I moved along a continuum of research positions from independent observer to action researcher (Walsham and Sahay 1999). Although this research has critical ambitions, the account presented here is a broadly interpretive one (Orlikowski and Baroudi 1991; Walsham 1993), reflecting the view that we need to understand in order to be critical. In this way, it attempts no more than to provide insight into a pervasive if subtly shifting, cognitiveemotional way of arguing and acting about IS implementation that has operated within the LAS community for more than a decade.

\section{A QUASI-IMPRESSIONIST TALE}

It is a few minutes past $11 \mathrm{a} . \mathrm{m}$. on November 22, 2000, as I walk into the control room at 220 Waterloo Road-a 5-minute walk from Waterloo station in London, and the headquarters of the LAS. The control room has a split-level design, which reflects the different activities carried out at either end of it. If you enter as I did, from the entrance nearest the mess room, you come in at the call taking end. This is where all emergency calls for an ambulance within the London area are received and dealt with.

There are 24 call taking positions, arranged in two concentric semicircles, at the apex of which, when not busy elsewhere in the room, sits the call taking superintendent, who is responsible for coordinating all call taking activity. With the exception of New Years' Eve, full staffing of the call taking positions is usually unnecessary, but on this particular Wednesday morning in November, an unusually high number of them are occupied. On either wall at this end of the room are digital displays, which show the percentage of emergency calls that have been connected within 5 seconds in the previous half-hour, and the number of calls that are waiting in the system to be answered. These displays are positioned so that, whichever call taking position you sit in, you can always see one of them - a reminder that the ambulance performance clock is always ticking. When calls are waiting in the system, pressure in the call taking area intensifies, and compliance with telephone answering protocols shows a corresponding decline.

High up on the wall facing the entrance, well above eye level for even the tallest person, is a glass panel. The room behind, which once was the projection room for a lecture theater, is now the home of the quality assurance unit. Entry 
to this room may be gained through a door off the control room, or from higher floors of the building via a back staircase, not visible from the control room. When seated at their desks, the members of the quality assurance unit cannot see or be seen through the glass panel. In this mode, the quality assurance advisors (QAAs) are usually listening in to calls as they are being taken, or replaying calls taken earlier, to monitor compliance with ambulance service protocols. Only when QAAs stand at the window can they be seen by call takers and see what is taking place in the call taking area. In this mode, they usually have some concern about what is happening outside. On this morning, however, the QAAs are out on the floor of the control room, as are a number of managers who one would not normally expect to find in this part of the building.

Peter, ${ }^{1}$ a young manager who has been with the LAS for less than 5 years, and hence a relative newcomer in a place where 10 to 30 years' service is the norm for many, is on duty near the far wall, under the glass panel. Standing there in his uniform, with his back very straight and a rather grim expression on his face, he reminds me of a young soldier who is just about to go into battle for the first time. I sense that on this particular day that is how it feels to him too.

"Where have you been?" he says. "You missed it! PDS came up at 9 o'clock and went straight back down again. We had to go back on the cards. We've only been live for 20 minutes!"

"How are things now?"

"Bit shaky," he says, "some of them are feeling quite anxious about it."

Breaks are more welcome than ever today, but they are in short supply in view of what is taking place. I speculate that the third floor smoking room, so used to the comings and goings of control room staff, must be almost as deserted this morning as in the first few hours of a New Years' Day. In an organization committed to preserving the health of the nation's capital, it is no small irony how many of its members are heavy smokers.

One of the call takers signals that he needs help, and Peter goes across to him. I walk about, observing staff as they do their work, as I have done on several earlier occasions. I recall some of the training sessions for this system implementation, remembering the efforts that were put into making sure that the LAS got it right this time. Karen is not busy with a call, so I ask her how she is coping.

"I think it will be OK," she says, "when we get used to it," her voice right now lacking conviction.

A call comes through, and as I stand beside her I see some of her problems. She starts to use the new system, but then abandons it, unsure in the pressure of the moment how to act in the automated environment that now structures her

${ }^{1}$ All names in this account are disguised. 
dialogues with callers. She tells the caller that an ambulance crew will be with them as soon as they can. This is all she is allowed to say, since she, like the other call takers, has no way of knowing what is now happening to her call at the other end of the room, or what ambulance availability is like at any given moment. The caller hangs up, and she has another go with the new system, now that the major pressure is off.

"Where are all the managers?" she says. "It's just like last time-we're all here in the thick of it, but there's no sign of any of them!"

At least this time they did not do it at 2 o'clock in the morning, so the chances are that most of the managers are in the building somewhere. She finishes with the new system, replying "unknown" to the questions she did not ask. Another call comes through, and she asks for my help with it. Her concern about what she is trying to do is very visible, and her colleagues on either side are busy. I know how dangerous it could be if I were to advise her, and she does too, but right now her anxiety is clouding her judgement. I tell her I will get someone, and return in seconds with one of the managers in the room.

The tension is palpable in the call taking area today. The more established members of the service seem to be experiencing it the most, but then they have been here long enough to remember. The others will only have heard about it, very vividly no doubt, as I have heard the telling of the tale myself on many occasions. One call taker is conspicuous by her calmness. I stand and watch and listen to her for a while, noting how she and the new protocols seem to be operating together in a way that clearly gives her much satisfaction. Her body language, her tone of voice, and the expression on her face all suggest she finds what she has to do now significantly preferable to what she had to do before, but there is no opportunity to ask her. Calls keep coming through to her, the operator no doubt having spotted how quickly she is dealing with them, and when she does not have a call, her colleague next to her keeps asking for her help, despite the seniority reflected in his rank markings when compared with hers. He, too, has spotted how comfortable she is today.

I make my way up to the other end of the room. $U p$ is relevant in this context, for the room has a hierarchy built into it that reflects perceptions built up in the service over many years about which work is the more important. You have to go up three steps to the sector end of the room, but it also off limits for call takers, so that only the most thick-skinned of them will approach a busy allocator to ask if an ambulance has been assigned to their call. Instead, when they get ETAs, call takers follow the established procedure, in which the call taking superintendent makes the enquiry to the sector. As you reach the top of the steps, the SOO's (senior operations officer) desk is to your left. The SOO sits with his back - all are men - to the call taking area, looking out over the sectors, even though he is manager for the whole room, and indeed manager for the entire service overnight, when some of the staff call him "Mister LAS." 
When he leaves his desk, he walks around the sectors, but rarely, if ever, chooses to go downstairs - into the call taking area-unless he is leaving the room. The digital wall displays are here too, so that the sectors may judge how the workload is building up.

Most of the managers are up here, standing in the center, with the four arms of the sector desks radiating out from them, in an X-shape. There are two sector teams, each with four desk positions, facing one another on each of the four arms, reflecting the seven sectors, with one spare, into which London is divided for ambulance service purposes. Here, the calls are allocated to ambulance crews, who at any given time may be either on station, awaiting a call, or on the road, attending one.

"How is it going up here?" I ask.

"OK so far, but it's early days."

Automation barely touches existing methods of working for sector teams, nevertheless they must access the additional information now recorded during call taking. There are some moans up here, that the changes required are more cumbersome for them than for call takers, that they are the losers in all of thisnot a position the sectors are accustomed to in their relations with call takers. I wonder about winners and losers as I think about how the service might go on from here. Nevertheless, on the sectors as well, they know what is at stake today. Many of them remember, and again, those that did not experience it have been told. It is as though people in the room feel they are in a goldfish bowl, with the world looking in, waiting to pounce if they make a mistake.

One of the uncanny recollections that flashed through my mind when they set the date for changeover to the new system was the event that occurred in Dallas, Texas, 37 years ago today. I suspect that few, if any, in the room have made that connection. For it is not the death of Kennedy they are remembering, but the deaths in London of 20 people in 36 hours in much more recent times. Today, again, the LAS is implementing a new computer system. Many are remembering what they call "the last time," what happened then, how the press descended on them and has continued to scrutinize their activities since, and the implications of that tragedy for them personally, and for the service and their role in it, in the intervening years.

Before one of the managers went off on leave, she said to me: "No doubt there are a few down there that would dearly love to see the whole thing go pearshaped, but even they would not really want to see us get remotely close to that sort of thing again!"

Rachel is in Kenya today, and I wonder if it has crossed her mind what is happening here. I think it will have. In the weeks leading up to this implementation, I felt her blood pressure rise on several occasions, when she believed the project was following a course of action that might mean she would have to live through the events of October 1992 again. 


\section{DISCUSSION}

The narrative tale describes the day the LAS installed their PDS system. This IS implementation was a response to the review of ambulance performance standards, in which call prioritization was introduced. Although the LAS had implemented another computer system between 1992 and 2000, the CTAK system in 1996, key aspects of the PDS implementation brought back memories of LASCAD in ways that CTAK did not. These issues are explored in a comparison of the way anxiety (of varying intensities) and improvisation (to varying degrees) interpenetrated in these three IS projects, by drawing on the theoretical model outlined earlier. Each of the projects is discussed in turn, emphasizing the extent to which improvisation was supported in the ways of arguing and acting about technology, and then drawing attention to the way that mood infused this activity, shaping actors' moves and an outcome of them.

The research suggests that while improvisation may be common in manual methods of working in organizations (Weick 1998), when information systems are introduced to support working practices, some cleansing of improvised activity takes place (Ciborra 1999), which may be appropriate in time-pressured environments (Weick 1998). So cleansing is a move that need not heighten anxiety about IS implementation. Moreover, the systems introduced provide new opportunities for improvised activity (Orlikowski 1996).

\subsection{Anxiety and Improvisation in Discursive Practices at the LAS}

Weick (1998) argues that improvisation is common in public sector organizations, particularly on the front line, and that it also occurs in psychotherapy, medical diagnosis, and combat. The control room of the LAS may, if we stretch our imaginations a bit, be seen as a site that brings all of these disparate settings together. In work that involves dealing with distressed callers, as they try to give details of a medical condition, and responding to patients, for whom minutes can make the difference between life and death outcomes, staff combine general medical know-how with ad hoc behavior in uncertain and unpredictable conditions. There are, for example, no guarantees about how much information will be available, about an incident, when it will become available and in what order, all of which affect both patient care and vehicle crew safety when dealing with the incident. In such an environment, improvisation and anxiety become very entangled. 


\subsubsection{LASCAD—When Technology Seemed to Make No Sense}

Previous accounts of the LASCAD development argue that limited staff participation gave rise to a system that lacked the near perfect knowledge it relied on of vehicle locations and crew/vehicle status (for example, Page et al. 1993). In the manual system, on the other hand, control room staff developed an intuition for where vehicles might be and what crews were doing, so they knew more than the knowledge they received in radio calls from crews confirming crew/vehicle status. In this way, their allocation decisions were skillful, improvised ones, in that they knew how to contact and mobilize a crew even though the formal knowledge documented on the paper in their activation boxes gave them only a skeletal picture of how resources were deployed. The allocators' bricolage was poorly mimicked by the LASCAD system, so what it did

was to give you lots of exception reports, and we were just inundated by exception reports...all of these things were just coming up by the screenload, pages and pages and pages of them (Interview with manager involved in the LASCAD implementation).

Thus the LASCAD system tried to access the tacit knowledge of its users, through the use of structured routines and formal procedures. For staff in an ambulance control room who were used to dealing with changing circumstances intuitively using voice communications with their colleagues, this method of working was both too alien and too demanding. So the LASCAD system only managed to automate incompetent behavior and in the time-pressured environment of an ambulance control room, it very quickly and disastrously engaged the backlash of experience, in which the data in the system ceased to have any meaning at all (Ciborra 1999).

\subsubsection{LASCAD—How Moves Intensified the Mood}

In his account of the Mann Gulch disaster, Weick (1993) argues that structures and actions can destroy as well as construct one another. In this way, he suggests that fear or panic can precede a loss of organization, but also that a loss of organization can intensify fear. The LASCAD implementation may be seen as an attempt to replace established methods of working with an alternative form that precipitated a loss of organization when the system went live. By removing the allocators' activation boxes, breaking up the area based teams, and rearranging the control room layout (Page et al. 1993), staff had no obvious 
fallback position when they were unable to improvise effectively in the new environment of automation. Staff anxiety about the new arrangements preceded the loss of organization, but when the extent to which they were unable to work with the new system became apparent, panic started to break out in the control room.

Some people would take it [the call] on paper because the screen had locked up, and some people would take it on the computer, and some people wanted to assign vehicles and you're saying "stop assigning vehicles, only the sector, the sector desk can assign the vehicles".... But it got to the stage where so many people were doing so many different things that it was starting to get slower and slower and slower (Interview with staff member involved in the LASCAD implementation).

Over a period of several hours, they lost their sense of organization, so that:

that morning of the crash, I mean when people were just, just coming on and off duty in tears-people that came off duty were just like in floods of tears - it was awful, it really was. It was like it was a nightmare, an absolute nightmare (ibid).

In this scenario, rather than actions creating structures, which shaped further actions in which an idea was converted into reality, both the capacity to act and the system that was needed to shape that action collapsed together. A loss of identity, which could not be rebuilt by falling back on manual arrangements, set panic free in the control room, with the result that an idea was converted into something monstrous. So the LAS was forced back on more established methods of working and away from an innovation which, with more attention to the cognitive-emotional dimensions of structuring, might have brought considerable benefits to the service in terms of its speed of response to emergency calls.

\subsubsection{CTAK-When Making Sense Was About Speeding Up}

During the CTAK project, a joint venture between IT staff and a user group designed a bespoke computer system to provide automated support for a limited set of control room activities. In this approach, most of the existing manual methods of working were retained, but where automated support was provided (for call taking activities) the focus was on getting this work done faster. In this way, the CTAK project was a response to ORCON standards, in which speed of 
response was the compelling theme. In effect, the non-graphical, form-based approach to call data entry in the CTAK system attempts no more than to replicate the previous manual method of form filling, and to speed it up, by including pick lists and an online gazetteer.

Thus the CTAK implementation sought to avoid the automation of incompetent behavior, but it did so through some cleansing (Ciborra 1999) by those who would use the system, which restricted certain interpretations and actions while supporting others. There are, for example, some limitations to the data values that the CTAK system will accept, although, in general, users negotiated with designers to include an other category on pick lists. Moreover, there are some in-built notions about the order in which information should be obtained from a caller so that the minimum details needed to despatch an ambulance are given priority during the conversation. This effort, then, suggests that it is possible to put some limits on support for improvisation without falling victim to the backlash of experience, in which such restrictions endanger competent behavior. Moreover, the case suggests that such limitations may be appropriate in the time-pressured environment of an ambulance control room, since the time available for improvisation may limit the degree to which it can be accomplished (Weick 1998).

\subsubsection{CTAK-Attending to the Mood by Reconstructing Social Relations}

I argue elsewhere (McGrath 2002) that actors approached the CTAK project in an anxious mood as they recalled the tragic events of October 1992. Moreover, I suggest that their anxiety was an outcome of the LASCAD implementation, reflecting their fears of failing again with information technology and of sabotage reoccurring (as alleged in the minutes of evidence to House of Commons Select Committee). Unlike LASCAD, the CTAK development made no attempt to automate the process of resource management, reaffirming the task orientations of both ambulance allocators and vehicle crews. Rather CTAK focused on automating call takers' work in an approach to structuring called the Golden Circle, which isolated those who were directly affected by the implementation and built strong social ties among them (for a full account, see McGrath 2002).

In attending to who needed to be involved in the CTAK project and who did not, and to what participants' contributions might be, control room staff were able to negotiate the strangeness (Weick 1993) of IS implementation. Such strangeness arose from their limited participation, whether by accident or design (Introna 1997), in the LASCAD development, as well as from their experiences 
of trying to work with the system once it went live. In this way, the CTAK project was a way of organizing that reduced anxiety about IS implementation at the LAS, and made the use of an information system possible for its staff-a way of attending to anxiety by reconstructing social relations so that sense making could occur (Weick 1993). Moreover, when problems with the CTAK system occur during live running, falling back to manual methods is straightforward. Some anxiety may be experienced as calls take longer to answer, but the identities that shape action remain intact, and so panic is avoided.

\subsubsection{PDS-When Making Sense Meant Being Disciplined}

Almost 10 years after the LASCAD implementation, rising call volumes and more demanding performance targets for UK ambulance services mean that the time available for emergency responses continues to decrease. Implementation of the PDS system in November 2000 may be seen as a move away from improvised responses to emergency calls. PDS, like CTAK, addressed call taking activities as its central concern, and in this way the manual box method for managing resources continued to operate. Nevertheless, PDS is a packaged application, which required a greater degree of compromise about how members of staff carry out their work than was necessary when CTAK was developed. PDS, like LASCAD, provides a formal, disciplinary structure for its users to follow, it has a rich functionality to enable prioritization of calls, and it is a Windows based application. Thus the embedding of PDS within the CTAK system is one in which the limits to interpretation and action were further refined. Thus far, pressures to perform have not pushed such cleansing efforts to the point where the backlash of experience has started to endanger competent behavior once more, as in 1992.

\subsubsection{PDS-Attending to the Mood by Focusing on New Meanings}

The narrative tale indicates an anxious mood in the control room on the day PDS was implemented, as memories of LASCAD surfaced once more. On this particular day, control room staff kept their anxiety at bay by sticking together, as Dodge's colleagues Rumsey and Sallee did at Mann Gulch. Call takers are seen to be helping one another out, managers and QAAs, who would normally be on duty elsewhere, are on hand in the control room. I, as observer, am called upon by Karen to lend a hand. Weick argues that, "Perhaps it's more important that you have a partner than an organization when you fight fires" (1993, p. 642). On the day that PDS was implemented, emergency workers in the LAS control room appeared to have both. 
Furthermore, when PDS did not come up at 9am as planned, a standby procedure was in place, in which staff could revert to the previous card-based method of prioritizing emergency calls, so that operations could continue without interruption. By installing a card-based version of the PDS system at first, the transition to the automated version was less traumatic than when LASCAD was implemented because staff had begun to work out, while using the cards, what prioritizing calls meant for their existing ways of organizing. So they had started to adjust their structure in line with new meanings of responding to patients based on clinical need or despatching by priority.

My observations of working practices reveal different responses to a call prioritization regime. Many staff members comply with the protocols inscribed within PDS, accepting them as the norm. Although some find them easy to use, others feel stressed by them, and a few are antagonistic toward the QAAs. At times, control room staff bypass or override the disciplinary mechanisms, adopting them as guidelines only. Some patterns have started to emerge as to which protocols and which clinical priorities they find inappropriate, and QAAs follow up these cases and issue revised instructions periodically. A small group questions more fundamentally the legitimacy of call prioritization, suggesting that it lengthens the process of responding to calls and that the LAS does not have the resources to deal with this outcome. These responses are cognitiveemotional ones, in which individuals feel a heightened sense of what the new world means for them, which in general is leading them to develop the social ties needed to support new meanings.

\section{CONCLUSIONS}

This research explores how anxiety (of varying intensities) and improvisation (to varying degrees) interpenetrated in three IS projects at the LAS during the last 10 years. In this way, it examines how experience of a tragedy can influence future encounters with similar situations. Moreover, in adopting a Foucauldian concept of discourse, it addresses how social institutions as well as local actors' memories inform such encounters. In this view, institutions such as the Department of Health and the popular press are seen as shaping discursive practices at the LAS, in ways that mandate technology deployment (for example, Chapman 1996) while constraining the pace at which it occurs by heightening anxiety about service performance.

Drawing on Weick's (1993) arguments about structuring for resilience, I suggest that an unstable form of structuring was evident during the LASCAD implementation, in which actions and structures destroyed one another, and anxiety intensified to fear and panic. Although allocators' tools - their activation boxes - had been taken away, they had not dropped them (Weick 1996) either 
cognitively or emotionally, and so they were unable to mobilize the LASCAD system to enact a form of structuring that was simultaneously constitutive and destructive. Arguing further that fear has an especially long half-life (Harlos and Pinder 2000), I suggest that anxiety surfaced again as actors approached the CTAK and PDS implementations. However, in these later efforts, they attended to their anxiety by adopting more resilient forms of structuring, in which they focused on clarifying social ties (CTAK) and on clarifying meanings (PDS), so as to build new ways of structuring at the same time that old ones were being destroyed.

In the CTAK implementation, the form of automated support for call taking activity very closely matched the previous paper-based method. Although some cleansing occurred, nevertheless the joint venture between user and IT staff supported a significant degree of improvised activity in the new environment. In the PDS effort, more demanding standards for ambulance service performance reduced the time available for improvised responses to emergency calls. In implementing a packaged application, some further cleansing of improvised activity occurred, but a gradual transition to the new form of automated support eased its introduction. Moreover, the PDS system provides new opportunities for improvised activity during call taking and despatching of resources.

Overall, the outcomes from the three IS projects suggest that, as institutions reduce the time available for emergency responses, the LAS is introducing technology that progressively cleanses its operations of improvised activity, but, thus far, only in a discrete area. In this approach, the form that information systems are taking is becoming increasingly disciplinary, bringing the LAS closer over time to the panoptic model envisaged when LASCAD was implemented. In these moves, a more demanding mood of the general public is being counterbalanced against a less anxious mood at the LAS about its potential to deploy information technology.

In summary, then, this research argues that IS implementation is a way of arguing and acting which takes place in an emotional medium within a given community. In this view, the information system emerges as an accomplishment of the implementation efforts, which provides some degree of support, planned and emergent, for improvised performances during system use (Ciborra 1999; Orlikowski 1996). In an anxious medium, the form of automated support for improvisation, the degree of improvised activity that needs to be supported, and the time available for users of the system to improvise are all key issues to be addressed during IS implementation efforts and as ongoing activities during system use. Further research might explore these interrelationships when other moods, such as tedium or excitement, prevail. In this view, then, IS implementation in organizations is a delicate balancing act that requires constant attention to subtly shifting cognitive-emotional ways of arguing and acting framed by institutions. 


\section{REFERENCES}

Beynon-Davies, P. "Information Systems 'Failure': The Case of the London Ambulance Service's Computer Aided Despatch Project," European Journal of Information Systems (4), 1995, pp. 171-184.

Blumer, H. "What Is Wrong with Social Theory?", American Sociological Review (19:1), 1954, pp. 3-10.

Chapman, R. Review of Ambulance Performance Standards. London: Department of Health, July 1996.

Ciborra, C. Information Complexities: Challenging the Wisdom of Systems. Oxford: Oxford University Press, 2002.

Ciborra, C. "In the Mood for Knowledge: A New Study of Improvisation," Paper presented to the Social Study of Information Technology Workshop, London School of Economics, 19-20 March, 2001.

Ciborra, C. "A Theory of Information Systems Based on Improvisation," in W. Currie and R. Galliers (eds.), Rethinking Management Information Systems. Oxford: Oxford University Press, 1999.

Department of Health. Modernisation of Ambulance Services (HSC 1999/091), London, April 1999.

Department of Health. The Patient's Charter, London, November 1996.

Drummond, H. Escalation in Decision-Making. New York: Oxford University Press, 1996.

Financial Times. "When Failure Followed Failure," 26 February 1993, p. 10.

Fineman, S. Emotion in Organizations. London: Sage, 2000.

Foucault, M. Power/Knowledge: Selected Interviews and Other Writings 1972-1977, C. Gordon (ed.). Brighton, England: Harvester Press, 1980.

Harlos, K., and Pinder, C. "Emotion and Injustice in the Workplace," in S. Fineman (ed.), Emotion in Organizations. London: Sage, 2000.

Hasselbladh, H., and Kallinikos, J. "The Project of Rationalization: A Critique and Reappraisal of Neo-institutionalism in Organization Studies," Organization Studies, (21:4), 2000, pp. 697-720.

Heidegger, M. The Basic Problems of Phenomenology. Bloomington, IN: Indiana University Press, 1995.

Hougham, M. "London Ambulance Service Computer-Aided Despatch System," International Journal of Project Management (14:2), 1996, pp. 103-110.

House of Commons Select Committee on Health. Second Report on London's Ambulance Service, June 1995.

Introna, L. Management, Information and Power. London: Macmillan Press, 1997.

McGrath, K. "The Golden Circle: A Way of Arguing and Acting About Technology in the London Ambulance Service," European Journal of Information Systems (11:4), November 2002.

Mitev, N. "More Than a Failure? The Computerized Reservation Systems at French Railways," Information Technology and People (9:4), 1996, pp. 8-19.

Myers, M. "A Disaster for Everyone to See: An Interpretive Analysis of a Failed IS Project," Accounting, Management and Information Technologies (4:4), 1994, pp. 185-201.

Oatley, K., and Jenkins, J. Understanding Emotions. Malden, MA: Blackwell, 1996.

Orlikowski, W. "Improvising Organizational Transformation Over Time: A Situated Change Perspective," Information Systems Research (7:1), 1996, pp. 63-92.

Orlikowski, W., and Baroudi, J. "Studying Information Technology in Organizations: Research Approaches and Assumptions," Information Systems Research (2:1), 1991, pp. 1-28.

$\mathrm{Oz}$, E. "When Professional Standards Are Lax: The CONFIRM Failure and Its Lessons," Communications of the ACM (37:10), 1994, pp. 29-36. 
Page, D., Williams, P., and Boyd, D. Report of the Inquiry into the London Ambulance Service. South West Thames Regional Health Authority, 25 February 1993.

Pettigrew, A. "Longitudinal Field Research on Change: Theory and Practice," Organization Science (1:3), 1990, pp. 267-291.

Ryle, G. "Improvisation," in G. Ryle (ed.), On Thinking. London: Blackwell, 1979.

Van Maanen, J. Tales of the Field. Chicago: University of Chicago Press, 1988.

Walsham, G. "Interpretive Case Studies in IS Research: Nature and Method," European Journal of Information Systems (4), 1995, pp. 74-81.

Walsham, G. Interpreting Information Systems in Organizations. Chichester: John Wiley \& Sons, 1993.

Walsham, G., and Sahay, S. "GIS for District-Level Administration in India: Problems and Opportunities," MIS Quarterly (23:1), 1999, pp. 39-66.

Wastell, D., and Newman, M. "Information Systems Design, Stress and Organizational Change in the Ambulance Services: A Tale of Two Cities," Accounting, Management and Information Technologies (6:4), 1996, pp. 283-300.

Weick, K. "The Collapse of Sense Making in Organizations: The Mann Gulch Disaster," Administrative Science Quarterly (38:4), 1993, pp. 628-652.

Weick, K. "Drop Your Tools: An Allegory for Organizational Studies," Administrative Science Quarterly (41), 1996, pp. 301-313.

Weick, K. "Improvisation as a Mindset for Organizational Analysis," Organization Science (9:5), 1998, pp. 543-555.

\begin{abstract}
About the Author
Kathy McGrath is a doctoral candidate at the London School of Economics and Political Science. She has experience working as an information systems consultant in the public and private sectors, and as an information systems lecturer in higher education. Her teaching and research interests include information systems development and management, and IT and organizational change. Kathy can be reached by e-mail at k.m.mcgrath@1se.ac.uk.
\end{abstract}

